\title{
Article \\ Densification of Yak Manure Biofuel Pellets and Evaluation of Parameters: Effects on Properties
}

\author{
Jianbiao Liu ${ }^{1}$, Xuya Jiang ${ }^{1}$, Yanhao Yuan ${ }^{1}$, Huanhuan Chen ${ }^{1}$, Wenbin Zhang ${ }^{1}$, Hongzhen Cai ${ }^{1,2, *}$ and Feng Gao ${ }^{2}$ \\ 1 School of Agricultural Engineering and Food Science, Shandong University of Technology, \\ Zibo 255000, China; mosdut@163.com (J.L.); 18753364170@163.com (X.J.); yyhyyh994994@163.com (Y.Y.); \\ chhh2022@163.com (H.C.); zhangwenbinsdut@163.com (W.Z.) \\ 2 Zibo Energy Research Institute, Zibo 255000, China; gfeng1976@126.com \\ * Correspondence: chzh@sdut.edu.cn
}

check for updates

Citation: Liu, J.; Jiang, X.; Yuan, Y.; Chen, H.; Zhang, W.; Cai, H.; Gao, F. Densification of Yak Manure Biofuel Pellets and Evaluation of Parameters: Effects on Properties. Energies 2022, 15, 1621. https://doi.org/ 10.3390/en15051621

Academic Editors: Mirela Ivančić Šantek, Božidar Šantek, Katarina Mihajlovski and Alok Kumar Patel

Received: 17 January 2022

Accepted: 18 February 2022

Published: 22 February 2022

Publisher's Note: MDPI stays neutral with regard to jurisdictional claims in published maps and institutional affiliations.

Copyright: (c) 2022 by the authors. Licensee MDPI, Basel, Switzerland. This article is an open access article distributed under the terms and conditions of the Creative Commons Attribution (CC BY) license (https:/ / creativecommons.org/licenses/by/ $4.0 /)$.

\begin{abstract}
This study was first conducted to comprehensively investigate the potential of yak manure as a raw material to prepare fuel pellets. The effect of different parameters such as binder, pressure, and moisture content on pellet density and diametric compressing strength was investigated using a laboratory single pelleting press unit. Results showed that increasing the pressure can help to obtain high-quality fuel pellets. The pellet properties (density and diametric compressing strength) initially increased and then decreased with moisture content increase. By contrast, binder was not identified to promote density and diametric compressing strength. The parameters were optimized using the response surface method with central composite design to obtain high-quality pellets. In conclusion, the use of yak manure as a raw material to make fuels can be considered a sustainable approach and can effectively be used to fulfill the energy and heating requirements of rural areas.
\end{abstract}

Keywords: yak manure; pelletization; parameters; physicochemical properties

\section{Introduction}

Energy is an important pillar for the sustainable socio-economic development of a country, coupling with an important basis for the survival and development of the human economy and society [1]. Presently, the use of energy in the world is still based on fossil energy such as coal, oil, and natural gas. However, global energy demand is increasing rapidly due to development, resulting in some disadvantages. On the one hand, the global energy reserves are decreasing day by day. Statistics show that oil, coal, and natural gas can be produced for 50,132, and 50.9 years, respectively, within the current production levels [2,3]. On the other hand, climate change issues such as the greenhouse effect brought about by the continued use of traditional fossil energy sources have made the conflict between energy and the environment increasingly prominent. These issues have made the awareness of the development of alternative energy sources an urgent matter. Biomass, as the fourth energy source after coal, oil, and gas, is the most attractive resource for its renewable, huge resources, low cost, and low emissions [4-6]. However, the low density, high costs of handling, transportation, and storage inhibit its use [7-9].

Densification is considered to be an effective way to improve these issues. It is a process of the dried and crushed biomass raw materials (for, e.g., agriculture and forestry residues, livestock manure, municipal solid waste, sewage, etc.) rearranged into specific shapes and sizes under a certain temperature, pressure, and moisture content [10]. The pellets with higher density, heating values, and low emissions can be used as feedstocks for cooking and heating [11]. Lots of studies concerning densification have been reported in previous literature. It was found that the properties of raw materials (e.g., types, particle size, moisture content, and composition), processing parameters (e.g., pressure and temperature), and additives/binders have a direct effect on the pellet quality (e.g., density, heating values, and durability) [12-18]. Among various parameters, pellets with high moisture result in 
dry matter loss during storage and transportation and also subject to early decomposition, according to Pradhan [8]. In addition, findings suggested an interaction between pressure and moisture content which could help improve the densification process, and therefore would need to be optimized in some feedstocks to ensure pellet quality [7].

The yak, an ancient and primitive species, is the only subfamily of bovids that thrives in the alpine pastures of the Tibetan Plateau. China is the country with the largest number and breeds of yak in the world, with more than 15 million in total, accounting for 95 percent. Among them, 93 percent of the yaks are distributed in the Tibetan Plateau. In previous literature, Degen et al. estimated that each yak would produce $786 \mathrm{~kg}$ of manure per year [19]. Due to economic reasons, most Tibetan families use yak manure for cooking and heating [20]. However, as with biomass such as straw, yak manure is irregular in shape, making it inconvenient to store and utilize.

With respect to the above introduction, this paper was first conducted using yak manure as the material to prepare fuel pellets. The effect of moisture content, pressure, and binders on pellet quality, which was exemplified by density and diametric compressing strength, was investigated. Meanwhile, the parameters were optimized using the response surface method with central composite design. The purpose of this study may be helpful for further efficient application of yak manure.

\section{Materials and Methods}

\subsection{Materials}

Yak manure was used as the raw material and two binders, namely calcium lignosulphonate (CL) and potato starch (PS), were used to prepare fuel pellets.

Yak manure was manually collected from the pastoral area located in Rikaze city, Tibet, China. The fresh manure was air-dried for 7 days and then crushed and sieved to sizes between 0.15 and $2 \mathrm{~mm}$. Subsequently, it was placed in a drying cabinet under $105 \pm 2{ }^{\circ} \mathrm{C}$ for $12 \mathrm{~h}$ to achieve a constant weight. After that, all the raw materials were stored in sealed plastic bags for further use.

Two binders, calcium lignosulphonate and potato starch were purchased from Shanghai Macklin Biochemical Co., Ltd., Shanghai, China.

\subsection{Properties of Yak Manure}

The proximate analysis of yak manure, including moisture content (MC), volatile matter (VM), and fixed carbon (FC), was carried out according to a Chinese standard namely Proximate Analysis of Solid Biofuels (GB/T 28731-2012) using a SDTGA-8000 thermogravimetric analyzer (proximate analyzer) (SUNDY, China) [21]. The ultimate analysis of carbon $(\mathrm{C})$, hydrogen $(\mathrm{H})$, nitrogen $(\mathrm{N})$, and sulfur $(\mathrm{S})$ was determined by the elemental analyzer (Vario EL Cube). In addition, the weight percentage of oxygen (O) was estimated by applying the following formula:

$$
\mathrm{O} \%=100 \%-(\mathrm{C}+\mathrm{H}+\mathrm{N}+\mathrm{S}) \%
$$

All the above results have been shown in Table 1.

Table 1. Properties of yak manure.

\begin{tabular}{ccccccccc}
\hline \multicolumn{4}{c}{ Ultimate Analysis (\%) } & \multicolumn{4}{c}{ Proximate Analysis (\%) } \\
\hline $\mathrm{C}$ & $\mathrm{H}$ & $\mathrm{O}$ & $\mathrm{N}$ & $\mathrm{S}$ & $\mathrm{MC}$ & $\mathrm{VM}$ & $\mathrm{FC}$ & $\mathrm{AC}$ \\
31.88 & 4.43 & 62.32 & 1.37 & 0.00 & 7.89 & 47.43 & 10.32 & 34.36 \\
\hline
\end{tabular}

MC: moisture content; VM: volatile matter; FC: fixed carbon; AC: ash content.

\subsection{Testing Equipment}

As illustrated in Figure 1, pellets were prepared in a single pelleting press unit consisting of a plunger with $19.8 \mathrm{~mm}$ in diameter and $40 \mathrm{~mm}$ in height and a cylinder die with a diameter of $20 \mathrm{~mm}$ and a length of $30 \mathrm{~mm}$. The plunger, connected to a computerized 
electronic universal testing machine (WDW-10G, Tianchen Testing Machine Manufacturing Co., Ltd., Jinan, China), provides the necessary compression load on the sample.

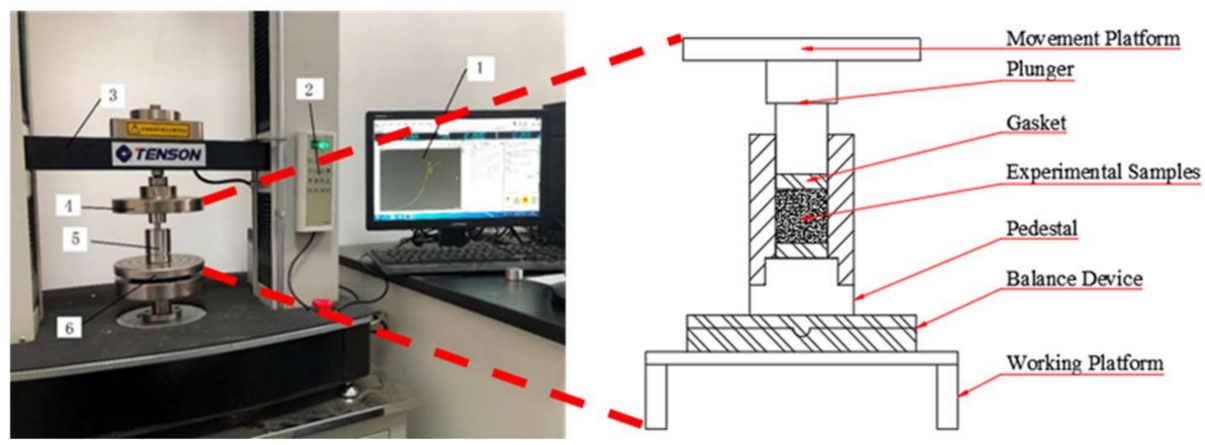

Figure 1. Schematic illustration of pelleting, 1; Computer, 2; Control bar, 3 and 4; Movement platform, 5; Pelleting unit, 6; Balance device.

\subsection{Experimental Design}

\subsubsection{Single Factor Test}

In the present study, the effects of various parameters, i.e., pressure, moisture content, binder types, and binder addition were considered. Meanwhile, the levels of pressure were $50,100,150,200$, and $250 \mathrm{MPa}$, moisture content of $0.5,5.5,10.5,15.5$, and $20.5 \%$, and the addition of binder was $0,1.5,3$, and $4.5 \%$, respectively. Firstly, the influence of pressure was considered under the condition of raw material with initial moisture content $(0.5 \%)$ and no binder added. Subsequently, the effect of moisture content was considered, again without the addition of binder, based on the previously obtained best pressure. Finally, the effect of binder species and addition was studied based on the best pressure and moisture content.

\subsubsection{Response Surface Methodology Analysis}

Response surface analysis is a statistical method that uses reasonable experimental design methods and obtains certain data through experiments, uses multiple quadratic regression equations to fit the functional relationship between factors and response values, and seeks optimal process parameters through the analysis of regression equations to solve multivariate problems [22]. In the present study, the parameters (pressure, moisture content, and binder addition) were optimized by using central composite design (CCD).

The data were analyzed using a second-order polynomial model with the following equations [23]:

$$
Y_{i}=\beta_{0}+\sum_{i-1}^{n} \beta_{i} X_{i}+\sum_{i-1}^{n} \beta_{i i} X_{i}^{2}+\sum_{i-1}^{n-1} \sum_{j=i+1}^{n} \beta_{i j} X_{i} X_{j}
$$

where, $\mathrm{Y}_{\mathrm{i}}$ is the response variable representing, i.e., density or diametric compressing strength. $\beta_{0}$ is the regression coefficient of intercept, $\beta_{\mathrm{i}}$ is the linear coefficients, $\beta_{\mathrm{ii}}$ is the quadratic coefficients, $\beta_{i j}$ is the interaction coefficients, and $X_{i}$ and $X_{j}$ are the independent control variables.

\subsection{Methods}

\subsubsection{Adjustment of Moisture Content}

In the preparation stage, ultrapure water was sprayed evenly on the yak manure with a spray bottle based on the previously determined moisture content to prepare three different moisture contents. The mass of ultrapure water to be added was calculated according to the following formula:

$$
\mathrm{m}_{\mathrm{add}}=\mathrm{m}_{\mathrm{ini}} \frac{\mathrm{K}_{2}-\mathrm{K}_{1}}{1-\mathrm{K}_{2}}
$$


where, $\mathrm{m}_{\mathrm{add}}$ is the mass of the added ultrapure water $(\mathrm{g}), \mathrm{m}_{\mathrm{ini}}$ is the initial mass of raw material $(\mathrm{g}), \mathrm{K}_{1}$ is the initial moisture content (\%), and $\mathrm{K}_{2}$ is the targeted moisture content (\%), i.e., $5.5,10.5,15.5$, and $20.5 \%$.

In order to mix the ultrapure water added with the raw yak manure evenly, the raw materials after being adjusted were placed in sealed plastic bags.

\subsubsection{Preparation of Fuel Pellets}

Approximately 2-3 g of the weighed material was filled in the mold. The plunger moved down with the moving platform on the computerized electronic universal testing machine and then the material was compressed. Meanwhile, the working pressure rose gradually with the plunger's downward movement. Then, when the working pressure reached the desired pressure, i.e., 50, 100, 150, 200, and $250 \mathrm{MPa}$, the plunger stopped going down and held at constant pressure for $15 \mathrm{~s}$. Subsequently, the fuel pellet in the mold was removed. Then, the pellets were kept in a sealed plastic bag to prevent them from being affected by ambient moisture. After $1 \mathrm{~d}$, the weight and dimensions of the pellets were measured to calculate the density. After that, the durability test was conducted.

\subsection{Determination of Quality Properties}

\subsubsection{Density}

The density was calculated using the following Equation (4). For this purpose, the mass was measured with a digital balance. The lengths and diameters were measured by vernier caliper.

$$
\rho=\frac{4 \mathrm{~m}}{\pi \mathrm{D}^{2} \mathrm{~L}}
$$

where, $\rho$ is pellet density $\left(\mathrm{kg} / \mathrm{m}^{3}\right), \mathrm{m}$ is the mass $(\mathrm{kg}), \mathrm{D}$ is the diameter $(\mathrm{m})$, and $\mathrm{L}$ is the length $(\mathrm{m})$.

\subsubsection{Durability}

Durability is a measure of the relative ability of the fuel pellet to resist breaking during transport and handling, which is an important characteristic to determine the usability and storage performance of the fuel pellet [18,24,25]. Lower durability indicates that there are various problems in the structural integrity of the fuel pellet during handling, transportation, use, and storage. In other words, it means that the pellet has a higher tendency of breakage. Normally, durability consists of compressing strength and drop resistance and so on. Herein, compressing strength was used as the remarkable index to characterize durability for the present study.

During the preparation process, the pressure acts on yak manure come from the axial direction, resulting in the axial stress resistance being significantly higher than diametric stress resistance. Hence, the maximum compressive strength that the pellet can bear in the diametric direction is taken as the compressing strength. During the experiments, pellets were randomly selected for investigation. At least three replicates were conducted each time. The pellet was placed in a horizontal direction in a testing machine with a compression rate of $5 \mathrm{~mm} / \mathrm{min}$ until the pellet was crushed [26].

\section{Results and Discussion}

\subsection{Yak Manure Characteristics}

Identification of raw material compounds is essential for the production of fuel pellets. As a result of specific geographical areas, the yak manure probably had different characteristics in comparison to others. Table 1 shows the summary of physicochemical characteristics of yak manure. It can be found that the moisture content was $7.89 \%$. Volatile matter content was $47.43 \%$, generally considered acceptable for ignition and combustion processes [4,27]. Different from other biomasses, yak manure had a higher ash content (34.36\%) [28-30]. A higher ash content has the potential tendency to reduce the heating value. Fixed carbon content $(10.32 \%)$ indicated that yak manure possessed a rich $C$ content. The results were 
also confirmed by the ultimate analysis where C content measured $31.9 \%$. Moreover, the results of the ultimate analysis showed that $\mathrm{O}$ was the first element present in yak manure. The ratios of $\mathrm{O} / \mathrm{C}$ and $\mathrm{H} / \mathrm{C}$ are vital parameters to qualify fuel composition and are usually used to compare different biofuels, which were found to be 1.95 and 0.14 , respectively. These lower ratios are a side reflection of the greater energy content of the biomass [31]. Whereas the $\mathrm{S}$ and $\mathrm{N}$ were found to be in lower proportion, i.e., $0.00 \%$ and $1.37 \%$, reflecting low $\mathrm{NO}_{x}$ and $\mathrm{SO}_{x}$ emissions during combustion. These results also indicated that the fuel pellets made by yak manure are valuable fuel for thermal utilization.

\subsection{Analysis of Single-Factor Test Results}

\subsubsection{Effect of Pressure}

The effect of pressure on pellet density and diametric compressing strength is shown in Figure 2. As depicted in Figure 2, the density and diametric compressing strength increased continuously with the increase of pressure. It was noteworthy that the density increased rapidly with the lower pressure, while slower growth was observed when the pressure was beyond $150 \mathrm{MPa}$. At the same time, during the experimental process, the compression and removal of pellets from the mold became difficult. Nevertheless, the density of all of the pellets met the requirement of commercial pellets [32,33]. Different from the density, the magnitude of the increase in diametric compressing strength remained nearly unchanged. Additionally, generally, higher pressure gave a more durable fuel pellet. In addition, the trends also confirmed that the pellet density increased exponentially with the pressure.

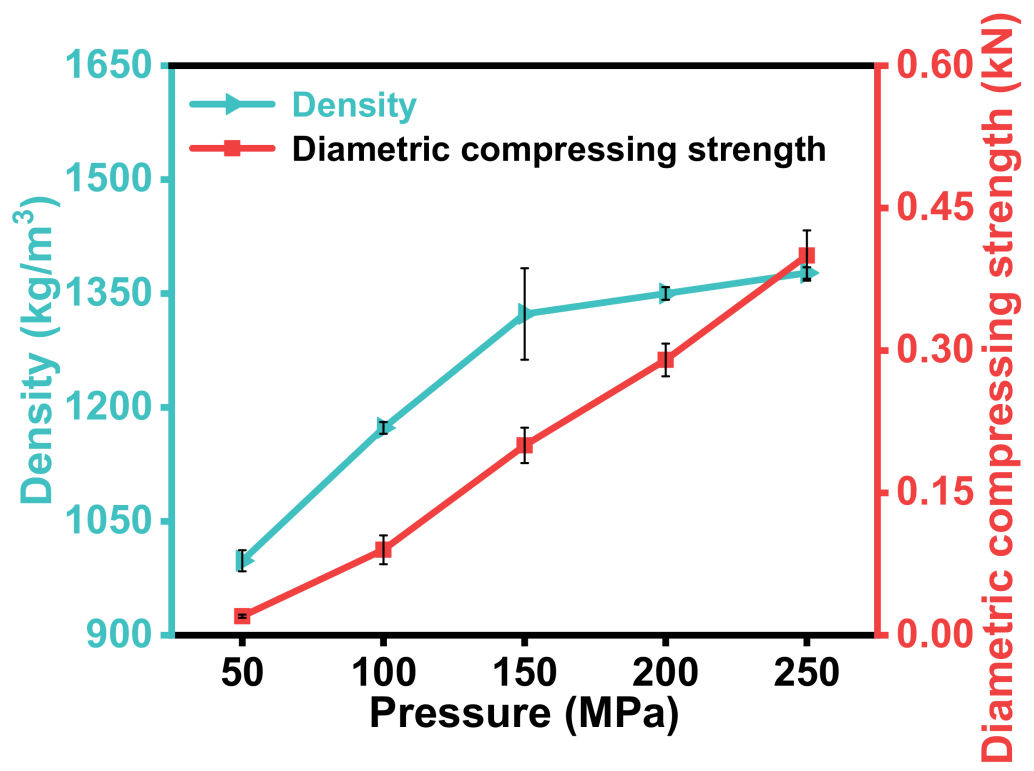

Figure 2. Density and diametric compressive strength of the pellet under different pressures.

During pellet production, pressure is regarded as a causing factor. Macroscopically, the essence of pelletization is the process of changing the arrangement structure of adjacent molecules and making them entangled and glued. Hence, the higher the pressure, the smaller the gap between adjacent molecules. To put it differently, it means that there is more raw material to accommodate per unit volume, thus resulting in higher density. However, as the pressure was further increased, the filling degree of the gap between molecules became higher, and the closer they were in contact with each other, resulting in a more stable movement of molecules. This is also why, as shown in Figure 2, when the pressure continued to increase from $150 \mathrm{MPa}$, the amplitude of density increasement gradually decreased, or even stayed stable. For diametric compressing strength, particles can interlock or fold about each other during the compressing process, resulting in interlocking bonds [34]. Hence, an increased pressure promotes the effect of interlocking, leading to a higher diametric compressing strength. 


\subsubsection{Effect of Moisture Content}

One of the important factors affecting the density is the moisture content. To obtain fuel pellets of reasonably high quality, pelletizing was performed at predetermined moisture content levels, $0.5,5.5,10.5,15.5$, and $20.5 \%$ under the optimal pressure (250 $\mathrm{MPa})$ based on the previous section. Figure 3 shows the effect of moisture content on density and diametric compressing strength. It can be found that yak manure fuel pellets had a higher density at all moisture content levels compared to the requirement of commercial pellets [32,33]. These trends revealed that both the pellet density and diametric compressing strength increased originally with the moisture content from $0.5 \%$ to $5.5 \%$, and then decreased when the moisture content was beyond $5.5 \%$. Thus, the appropriate moisture content for the yak manure pellet was chosen to be $5.5 \%$. This result seemed inconsistent with previous studies which showed that the density and diametric compressing strength of the fuel pellet had an optimum within the moisture content range of $10 \%$ to $15 \%$ [35].

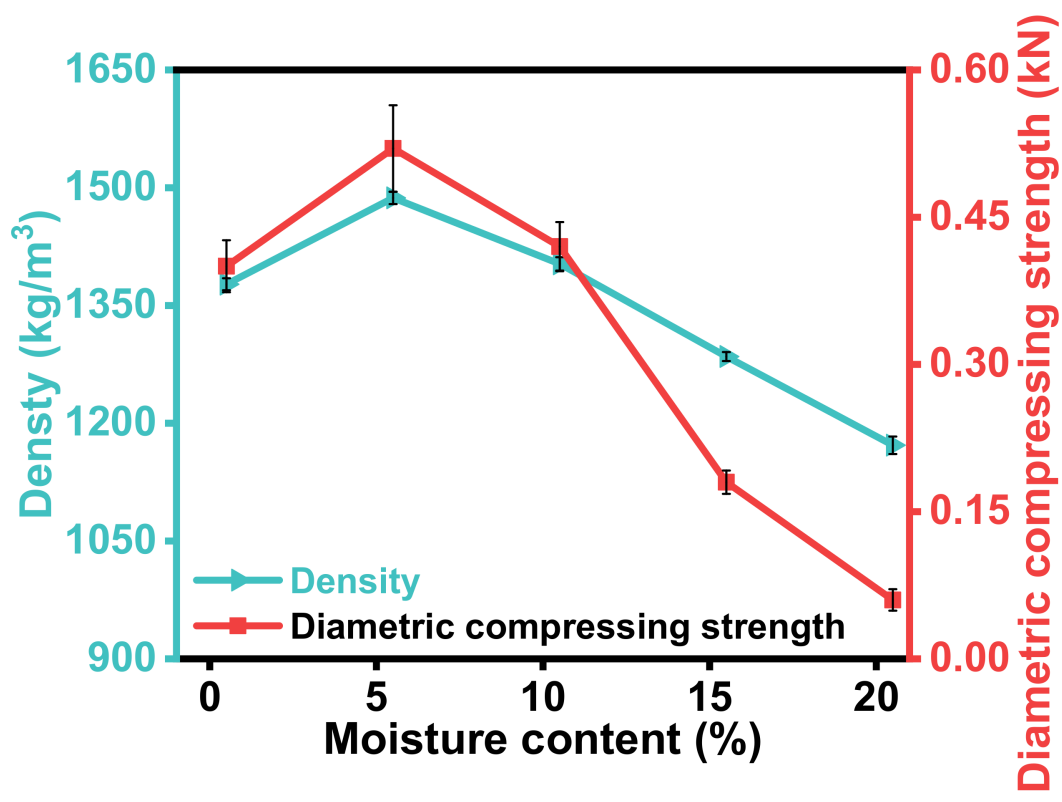

Figure 3. Density and diametric compressive strength of the pellet under different moisture contents.

It is well known that moisture acts as a binder and lubricant during the pellet production. On the one hand, water is needed for the softening of lignin and other binders. It can be clearly seen from Figure 3 that the density and diametric compressing strength were poor at lower moisture content. On the other hand, at lower moisture content, water filled the interstices of the particles and acted as a binder to strengthen, as well as promote bonding by increasing the contact area of particles. However, once the moisture content was increased beyond optimal conditions, it had a negative effect on the density and diametric compressing strength. The water surrounded the particle and prevented the release of its natural binders. The interpretation was also consistent with the trend shown in Figure 3, in which the density of the pellets was poor in lower/higher moisture content.

\subsubsection{Effect of Binders}

Various studies of binder addition for improving the quality of pellets have been reported [36-39]. A binder can form a bridge or cause a chemical reaction with particles, resulting in strong inter-particle bonding, leading to better strength and durability values of pellets. Note that the binder must be selected with adequate consideration of its cost and environmental friendliness.

Figures 4 and 5 present the effect of PS and CL binders on the density and diametric compressing strength. The results obtained seemed to be inconsistent with those reported in the previous literature $[40,41]$. The data revealed that both two binders had an incon- 
siderable effect on the density and diametric compressing strength. For the PS binder, the maximum increase in diametric compressing strength was $28 \%$ with $1.5 \%$ addition. However, the density showed a slightly decreasing trend with the increase of addition. Likewise, the other binder material CL showed little improvement in density. Although the increase in CL binder addition increased the diametric compressing strength, the maximum increase was only $9 \%$ with $4.5 \%$ addition.

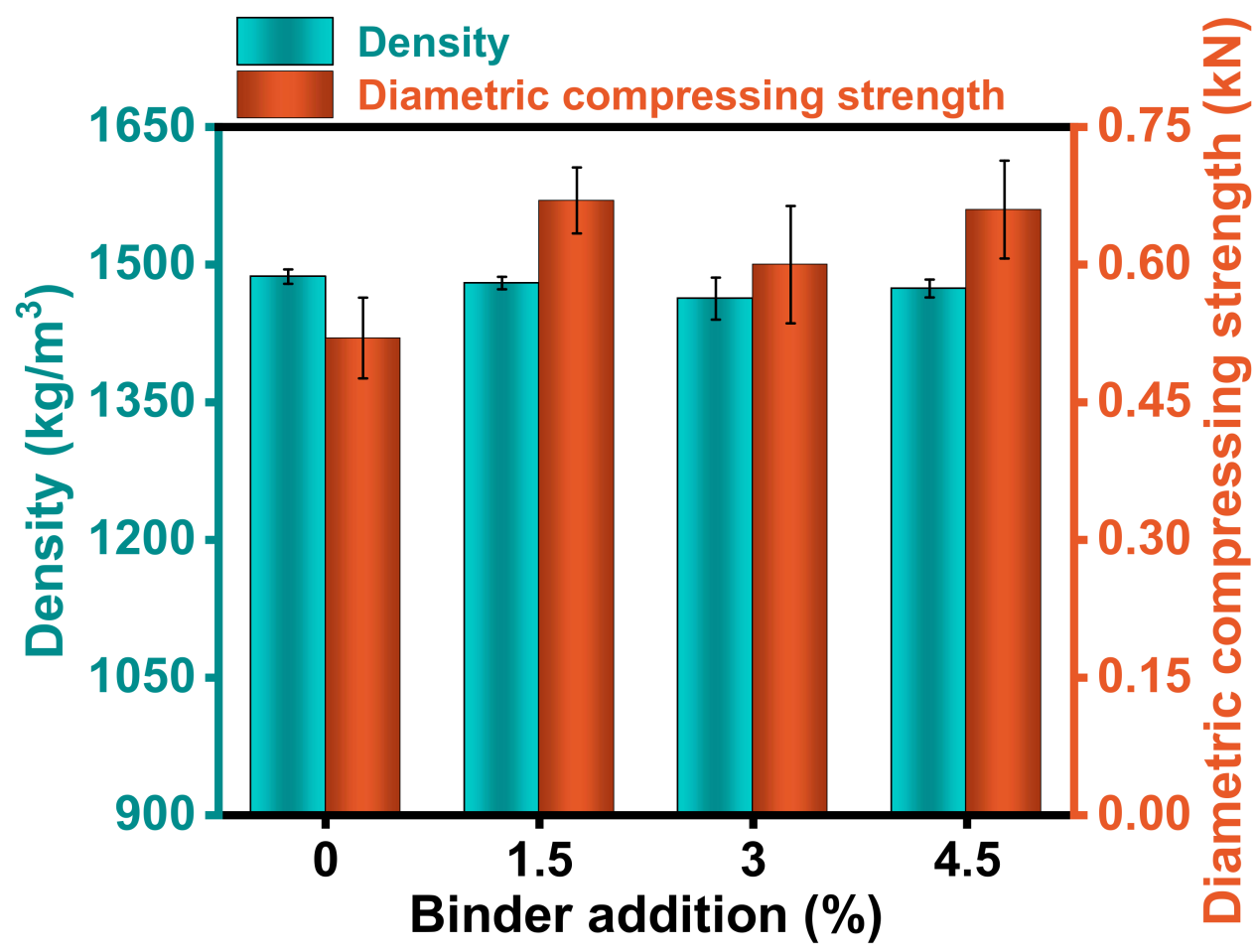

Figure 4. Effect of PS binder on the density and diametric compressing strength.

With Figures 4 and 5, the difference between CL and PS binders on density was less than $1 \%$. This behavior was different from the diametric compressing strength. A prominent effect on diametric compressing strength could be seen with PS binder addition as compared to CL binder addition.

Based on the above results, the fact that the binder addition could not improve the fuel pellet quality might be related to the characteristics of yak manure, that is to say, there might be a chemical layer on the surface of yak manure, which hindered the formation of a bridge or chemical reaction between binder and particles [10].

\subsection{Response Surface Methodology Analysis}

\subsubsection{Statistical Analysis and Model Fitting}

The levels of each independent variable were determined based on the results of the single-factor test. The intermediate levels of moisture content were the better parameters obtained from the single-factor test, and then the adjacent high level and low level were taken to form three levels, i.e., $0.5,5.5$, and $10.5 \%$. In addition, the single-factor test showed that the higher the pressure, the better the molding quality of the pellet fuel. However, the higher the pressure, the higher the energy consumption and time needed for pellet preparation, which increased the production cost of pellet fuel to some extent. Therefore, the pressure levels of 150,200, and $250 \mathrm{MPa}$ were chosen. As for the binder and binder addition, it was clear from the aforementioned single-factor experiments that there was no significant difference between the two binders. In consideration of cost and accessibility, PS was selected as the binder and the addition levels were taken as $1.5,3$, and $4.5 \%$. 
The preparation of the fuel pellet was carried out according to the experimental design matrix, and the obtained results of responses (density and diametric compressing strength) have been listed in Table 2. Meanwhile, each group of tests were repeated three times and the mean value was taken as the test result.

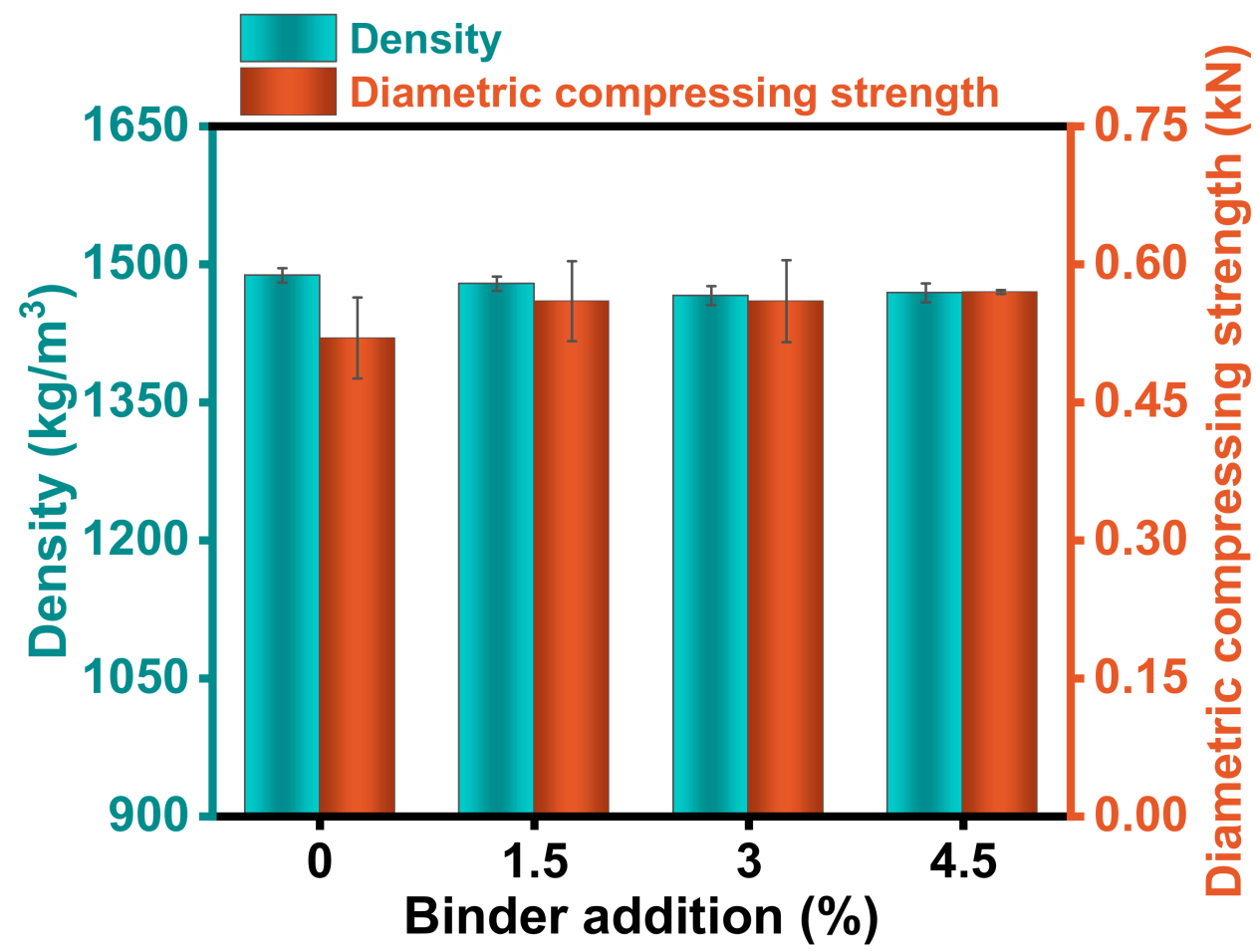

Figure 5. Effect of CL binder on the density and diametric compressing strength.

Table 2. Experimental design and results.

\begin{tabular}{cccccc}
\hline Run & \multicolumn{3}{c}{ Parameters } & \multicolumn{2}{c}{ Responses } \\
\hline & $\begin{array}{c}\text { Pressure } \\
\mathbf{( M P a )}\end{array}$ & $\begin{array}{c}\text { Moisture } \\
\text { Content } \\
\mathbf{( \% )}\end{array}$ & $\begin{array}{c}\text { Binder } \\
\text { Addition } \mathbf{( \% )}\end{array}$ & $\begin{array}{c}\text { Density } \\
\mathbf{( k g / \mathbf { m } ^ { 3 } )}\end{array}$ & $\begin{array}{c}\text { Diametric } \\
\text { Compressing } \\
\text { Strength (kN) }\end{array}$ \\
\hline 1 & 200 & 5.5 & 4.5 & 1479.86 & 0.46 \\
2 & 250 & 10.5 & 4.5 & 1423.43 & 0.40 \\
3 & 250 & 0.5 & 1.5 & 1417.06 & 0.35 \\
4 & 150 & 0.5 & 4.5 & 1391.21 & 0.29 \\
5 & 200 & 5.5 & 3 & 1466.89 & 0.49 \\
6 & 150 & 10.5 & 1.5 & 1413.47 & 0.43 \\
7 & 250 & 5.5 & 3 & 1474.40 & 0.52 \\
8 & 200 & 5.5 & 3 & 1470.93 & 0.46 \\
9 & 200 & 10.5 & 3 & 1402.34 & 0.41 \\
10 & 250 & 10.5 & 1.5 & 1397.60 & 0.38 \\
11 & 250 & 0.5 & 4.5 & 1463.56 & 0.46 \\
12 & 200 & 5.5 & 3 & 1475.65 & 0.48 \\
13 & 150 & 0.5 & 1.5 & 1303.40 & 0.17 \\
14 & 200 & 5.5 & 3 & 1474.28 & 0.50 \\
15 & 200 & 5.5 & 3 & 1473.86 & 0.48 \\
16 & 150 & 10.5 & 4.5 & 1418.97 & 0.44 \\
17 & 200 & 5.5 & 3 & 1483.22 & 0.48 \\
18 & 200 & 0.5 & 3 & 1415.33 & 0.34 \\
19 & 150 & 5.5 & 3 & 1450.73 & 0.28 \\
20 & 200 & 5.5 & 1.5 & 1488.87 & 0.53 \\
\hline
\end{tabular}


Subsequently, the above results of the responses were fitted with the Quadratic model. Additionally, the equations in terms of code factors are presented as follows:

$$
\begin{gathered}
\mathrm{Y}_{1}=945.6024+3.1235 \mathrm{X}_{1}+ \\
-55.5529 \mathrm{X}_{2}+3.3890 \mathrm{X}_{3}-0.0987 \mathrm{X}_{1} \mathrm{X}_{2}-0.0349 \mathrm{X}_{1} \mathrm{X}_{3}-1.7164 \mathrm{X}_{2} \mathrm{X}_{3} \\
-0.0052 \mathrm{X}_{1}^{2}-2.6688 \mathrm{X}_{2}^{2}+3.9146 \mathrm{X}_{3}^{2} \\
\mathrm{Y}_{2}=-1.0959+0.0126 \mathrm{X}_{1}+0.1002 \mathrm{X}_{2}-0.0739 \mathrm{X}_{3}-0.0002 \mathrm{X}_{1} \mathrm{X}_{2}+0.00002 \mathrm{X}_{1} \mathrm{X}_{3}-0.0034 \mathrm{X}_{2} \mathrm{X}_{3} \\
-0.000026 \mathrm{X}_{1}^{2}-0.003432 \mathrm{X}_{2}^{2}+0.016840 \mathrm{X}_{3}^{2}
\end{gathered}
$$

where $Y_{1}$ is the density of pellet $\left(\mathrm{kg} / \mathrm{m}^{3}\right), Y_{2}$ is the diametric compressing strength $(\mathrm{kN}), \mathrm{X}_{1}$ is the pressure (MPa), $X_{2}$ is the moisture content $(\%)$, and $X_{3}$ is the binder addition (\%).

To examine the accuracy and significance of the model, as well as the interactions between the process variables, the analysis of variance, ANOVA, was adopted. The complete results have been summarized in Tables 3 and 4 . The obtained results revealed a low $p$-value, i.e., $<0.0001$ and 0.0025 , showing the high significance of the selected model. From Tables 3 and 4 , it can be seen that the factors $X_{1}, X_{3}, X_{1} X_{2}, X_{2} X_{3}$, and $X_{2}^{2}$ had a $p$-value less than 0.05 , indicating model terms were significant for density. It also can be found that $X_{1}, X_{2}, X_{1} X_{2}, X_{1}^{2}$, and $X_{2}^{2}$ represented significant model terms for diametric compressing strength.

Table 3. ANOVA for model and respective model term: Density.

\begin{tabular}{ccccccc}
\hline Source & $\begin{array}{c}\text { Sum of } \\
\text { Squares }\end{array}$ & df & $\begin{array}{c}\text { Mean } \\
\text { Square }\end{array}$ & F Value & $p$ Value & \\
\hline Model & 37540.96 & 9 & 4171.22 & 18.71 & $<0.0001$ & Significant \\
$\mathrm{X}_{1}$ & 3930.39 & 1 & 3930.39 & 17.76 & 0.0018 & \\
$\mathrm{X}_{2}$ & 425.75 & 1 & 425.75 & 1.91 & 0.1971 & \\
$\mathrm{X}_{3}$ & 2453.37 & 1 & 2453.37 & 11.00 & 0.0078 & \\
$\mathrm{X}_{1} \mathrm{X}_{2}$ & 4872.00 & 1 & 4872.00 & 21.85 & 0.0009 & \\
$\mathrm{X}_{1} \mathrm{X}_{3}$ & 55.04 & 1 & 55.04 & 0.2469 & 0.6300 & \\
$\mathrm{X}_{2} \mathrm{X}_{3}$ & 1325.66 & 1 & 1325.66 & 5.95 & 0.0349 & \\
$\mathrm{X}_{1}^{2}$ & 464.37 & 1 & 464.37 & 2.08 & 0.1795 & \\
$\mathrm{X}_{2}^{2}$ & 12241.49 & 1 & 12241.49 & 54.91 & $<0.0001$ & \\
$\mathrm{X}_{3}^{2}$ & 213.34 & 1 & 213.34 & 0.9569 & 0.3510 & \\
Residual & 2229.50 & 10 & 222.95 & & & \\
Lack of fit & 2081.81 & 5 & 416.36 & 14.10 & 0.0057 & Significant \\
Pure error & 147.69 & 5 & 29.54 & & & \\
Cor Total & 39770.46 & 19 & & & & \\
\hline
\end{tabular}

Table 4. ANOVA for model and respective model term: Diametric compressing strength.

\begin{tabular}{ccccccc}
\hline Source & Sum of Squares & $\mathbf{d f}$ & Mean Square & F Value & $p$ Value & \\
\hline Model & 0.1429 & 9 & 0.0159 & 7.17 & 0.0025 & Significant \\
$\mathrm{X}_{1}$ & 0.0267 & 1 & 0.0267 & 12.05 & 0.0060 & \\
$\mathrm{X}_{2}$ & 0.0194 & 1 & 0.0194 & 8.76 & 0.0143 & \\
$\mathrm{X}_{3}$ & 0.0034 & 1 & 0.0034 & 1.56 & 0.2406 & \\
$\mathrm{X}_{1} \mathrm{X}_{2}$ & 0.0235 & 1 & 0.0235 & 10.60 & 0.0086 & \\
$\mathrm{X}_{1} \mathrm{X}_{3}$ & 0.0000 & 1 & 0.0000 & 0.0091 & 0.9259 & \\
$\mathrm{X}_{2} \mathrm{X}_{3}$ & 0.0053 & 1 & 0.0053 & 2.41 & 0.1519 & \\
$\mathrm{X}_{1}^{2}$ & 0.0117 & 1 & 0.0117 & 5.28 & 0.0444 & \\
$\mathrm{X}_{2}^{2}$ & 0.0202 & 1 & 0.0202 & 9.14 & 0.0128 & \\
$\mathrm{X}_{3}^{2}$ & 0.0039 & 1 & 0.0039 & 1.78 & 0.2114 & \\
Residual & 0.0222 & 10 & 0.0022 & & & \\
Lack of fit & 0.0208 & 5 & 0.0042 & 15.92 & 0.0043 & Significant \\
Pure error & 0.0013 & 5 & 0.0003 & & & \\
Cor Total & 0.1650 & 19 & & & & \\
\hline
\end{tabular}


It can be seen from the data in Table 5 that the values of coefficient of determination $\left(\mathrm{R}^{2}\right)$ were $94.39 \%$ and $86.58 \%$, respectively, demonstrating that the response values predicted from the data analysis software were reasonably close to the experimentally recorded values. It also indirectly revealed that the fitted equations had a high degree of confidence. Adequate precision measures the signal to noise ratio. Normally, a ratio greater than 4 is desirable [12]. The values of adequate precision in this paper were 16.8177 and 10.8856, indicating an adequate signal. To sum up the above, the model could be used to navigate the design space.

Table 5. Fit statistics.

\begin{tabular}{ccc}
\hline & Density & Diametric Compressing Strength \\
\hline Standard Deviation (Std. Dev.) & 14.93 & 0.0471 \\
Mean & 1439.25 & 0.4178 \\
Coefficient of Variance (C.V.) & 1.04 & 11.27 \\
Coefficient of Determination & 0.9439 & 0.8658 \\
( $^{2}$ ) & 0.8935 & 0.7450 \\
Adjusted $\mathrm{R}^{2}$ & 16.8177 & 10.8856 \\
Adequate Precision & &
\end{tabular}

\subsubsection{Three-D (3D) Surface Plot}

The 3D surface plot can intuitively reflect the strength of the interaction between factors (pressure, moisture content, and binder addition) and response values (density, diametric compressing strength), that is, the circular outline indicates that the interaction between the parameters in the response surface map is insignificant, while the oval or saddle outline indicates that the interaction is strong [22].

Figure $6 \mathrm{a}-\mathrm{c}$ present the effect of pressure and moisture content on density under constant binder addition of 3\%, the effect of pressure and binder addition on density under constant moisture content of $5.5 \%$, and the effect of moisture content and binder addition on density at a constant pressure of $200 \mathrm{MPa}$, respectively. Likewise, Figure 7 depicts the effect of the interaction between each two parameters on the diametric compressing strength.
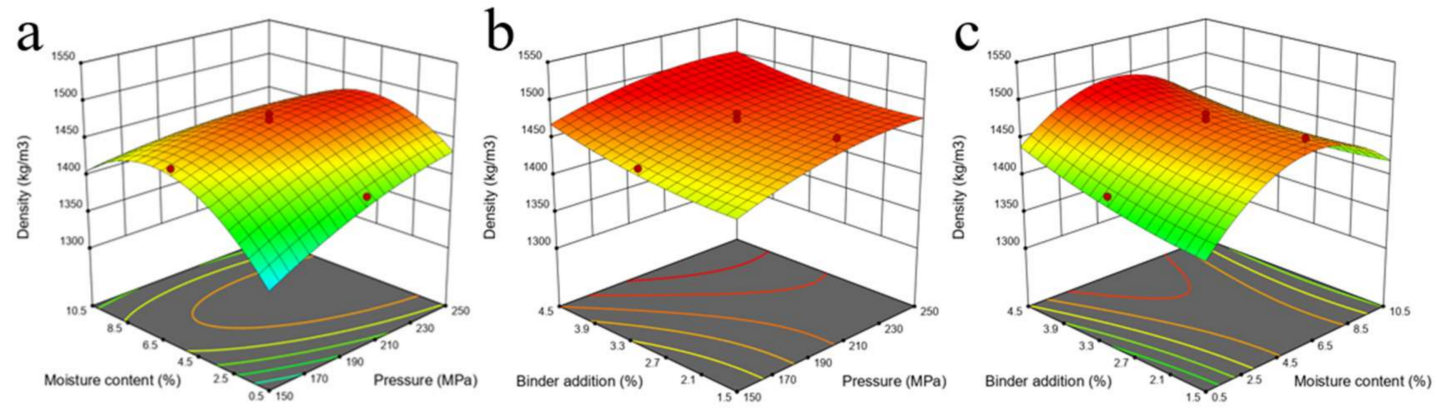

Figure 6. Three-dimensional surface plot and interactions of process variables on density. (a) Effect of pressure and moisture content at binder addition of 3\%; (b) Effect of pressure and binder addition at moisture content of 5.5\%; (c) Effect of moisture content and binder addition at pressure of $200 \mathrm{MPa}$.

It can be seen from Figures $6 \mathrm{a}$ and $7 \mathrm{a}$ that the interaction between pressure and moisture content was much stronger, both in terms of density and diametric compressing strength. Figure $6 b, c$ revealed a stronger interaction of moisture content with the binder compared to the interaction of pressure with the binder. Nevertheless, the presence of binder did not have a contributory effect in terms of density improvement. This was also consistent with the results obtained in Section 3.2.3. Likewise, as mentioned above, the binder added was more effective in enhancing diametric compressing strength than density. The combination of Figures $6 b, c$ and $7 b, c$ also confirmed these conclusions. 

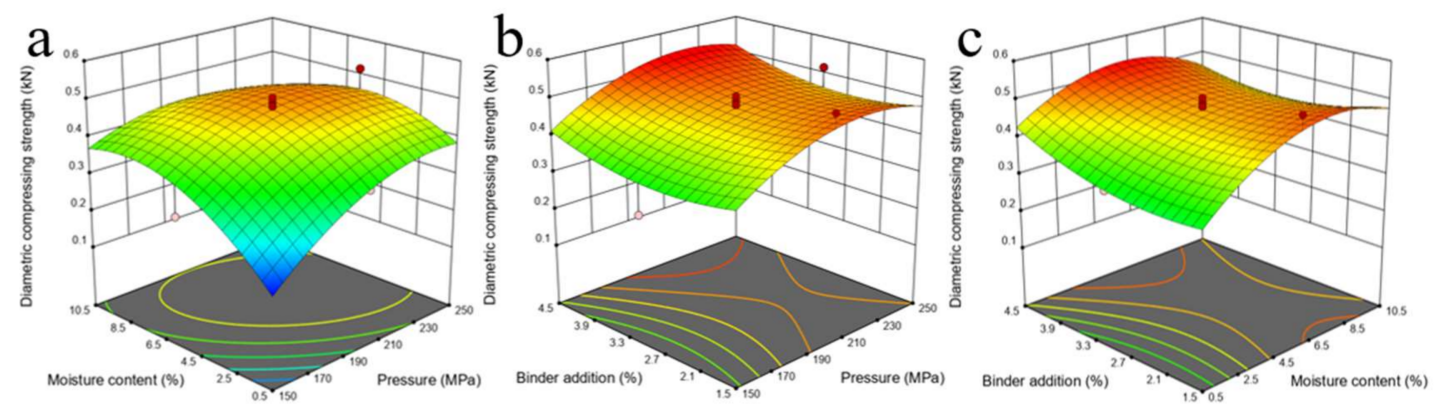

Figure 7. Three-dimensional surface plot and interaction of process variables on diametric compressing strength. (a) Effect of pressure and moisture content at binder addition of 3\%; (b) Effect of pressure and binder addition at moisture content of $5.5 \%$; (c) Effect of moisture content and binder addition at pressure of $200 \mathrm{MPa}$.

\subsubsection{Optimization of Process Variables and Validation of Result}

For a high-quality fuel pellet, optimization experiments were settled by setting the parameters (pressure, moisture content, and binder addition) in the range of previously described conditions for the selected model, for maximum density and diametric compressing strength. Under the circumstances, various solutions were generated. Only a partial solution was listed, for the sake of convenience. Tables 6 and 7 present the constraints and solutions, respectively.

Table 6. Constraints for optimization experiments.

\begin{tabular}{ccccccc}
\hline Name & Goal & $\begin{array}{c}\text { Lower } \\
\text { Limit }\end{array}$ & $\begin{array}{c}\text { Upper } \\
\text { Limit }\end{array}$ & $\begin{array}{c}\text { Lower } \\
\text { Weight }\end{array}$ & $\begin{array}{c}\text { Upper } \\
\text { Weight }\end{array}$ & Importance \\
\hline $\begin{array}{c}\text { Pressure } \\
\text { Moisture }\end{array}$ & is in range & 150 & 250 & 1 & 1 & 3 \\
$\begin{array}{c}\text { content } \\
\text { Binder addition }\end{array}$ & is in range & 0.5 & 10.5 & 1 & 1 & 3 \\
$\begin{array}{c}\text { Density } \\
\text { Diametric }\end{array}$ & maximize & 1303.4 & 1488.87 & 1 & 1 & 3 \\
$\begin{array}{c}\text { compressing } \\
\text { strength }\end{array}$ & maximize & 0.1721 & 0.5327 & 1 & 1 & 3 \\
\hline
\end{tabular}

Table 7. Optimization solutions.

\begin{tabular}{ccccccc}
\hline No. & $\begin{array}{c}\text { Pressure } \\
\mathbf{( M P a )}\end{array}$ & $\begin{array}{c}\text { Moisture } \\
\text { Content } \\
\mathbf{( \% )}\end{array}$ & $\begin{array}{c}\text { Binder } \\
\text { Addition } \\
\mathbf{( \% )}\end{array}$ & $\begin{array}{c}\text { Density } \\
\mathbf{( k g / \mathbf { m } ^ { 3 } )}\end{array}$ & $\begin{array}{c}\text { Diametric } \\
\text { Compressing Strength } \\
\mathbf{( k N )}\end{array}$ & Desirability \\
\hline 1 & 229.470 & 6.003 & 4.443 & 1500.880 & 0.543 & 1.000 \\
2 & 216.068 & 5.497 & 4.435 & 1501.976 & 0.537 & 1.000 \\
3 & 233.397 & 4.961 & 4.473 & 1505.968 & 0.536 & 1.000 \\
4 & 229.398 & 6.493 & 4.491 & 1497.847 & 0.533 & 1.000 \\
\hline
\end{tabular}

As can be seen from Table 7, the optimal solution selected implies that approximately a pressure of $229.47 \mathrm{MPa}$, moisture content of $6.00 \%$, and binder addition of $4.44 \%$ were capable of producing high-quality fuel pellets with a density of $1500.88 \mathrm{~kg} / \mathrm{m}^{3}$ and a diametric compressing strength of $0.54 \mathrm{kN}$. Considering the maneuverability of the experimental parameters, the optimal parameters were modified to $230 \mathrm{MPa}$ of pressure, $6 \%$ of moisture content, and $4.5 \%$ of binder addition. Under this, the density and diametric compressing strength can be reached at $1502.02 \mathrm{~kg} / \mathrm{m}^{3}$ and $0.57 \mathrm{kN}$. For verifying the accuracy of the prediction results, a validation test was conducted using the modified parameters, and the test results and errors were summarized in Table 8. The data presented in Table 8 show that 
there was virtually no difference between the predicted and actual experimental values, and the error in the results under all three trials was within $5 \%$. Hence, it also proved the reliability of the model for density and diametric compressing strength.

Table 8. Results of experiments and prediction.

\begin{tabular}{ccccccc}
\hline \multirow{2}{*}{ No. } & \multicolumn{3}{c}{ Density $\left(\mathbf{k g} / \mathbf{m}^{\mathbf{3}}\right)$} & \multicolumn{3}{c}{ Diametric Compressing Strength (kN) } \\
\cline { 2 - 7 } & Predicted & Experimental & Error & Predicted & Experimental & Error \\
\hline 1 & 1502.02 & 1436.21 & $4.38 \%$ & 0.57 & 0.55 & $3.51 \%$ \\
2 & 1502.02 & 1434.93 & $4.47 \%$ & 0.57 & 0.58 & $1.75 \%$ \\
3 & 1502.02 & 1446.45 & $3.70 \%$ & 0.57 & 0.58 & $1.75 \%$ \\
\hline
\end{tabular}

\section{Conclusions}

This paper was first conducted to comprehensively investigate the potential of yak manure as a raw material to prepare fuel pellets. Increasing the pressure can help obtain high-quality fuel pellets, but maintaining a balance between continuous growth pressure, quality, and cost is equally essential. The pellet properties initially increased and then decreased with moisture content. The binder had a slightly different effect on properties improvement. Optimum density and diametric compressing strength of $1502.02 \mathrm{~kg} / \mathrm{m}^{3}$ and $0.57 \mathrm{kN}$ were recorded at $230 \mathrm{MPa}$ pressure, $6 \%$ moisture content, and binder addition of $4.5 \%$. In conclusion, pellets made from yak manure can be considered an option to meet energy demands.

Author Contributions: Conceptualization, J.L.; methodology, J.L. and X.J.; software, J.L. and X.J.; validation, J.L., Y.Y. and W.Z.; investigation, J.L. and H.C. (Huanhuan Chen); resources, F.G.; writing-original draft preparation, J.L.; writing—review and editing, X.J. and H.C. (Hongzhen Cai); supervision, H.C. All authors have read and agreed to the published version of the manuscript.

Funding: This research was funded by the Foundation of Rikaze Science and Technology Plan Project (RKZ2020KJ03).

Institutional Review Board Statement: Not applicable.

Informed Consent Statement: Not applicable.

Data Availability Statement: Data are contained within the article.

Conflicts of Interest: The authors declare no conflict of interest.

\section{References}

1. Ibitoye, S.E.; Jen, T.C.; Mahamood, R.M.; Akinlabi, E.T. Densification of agro-residues for sustainable energy generation: An overview. Bioresour. Bioprocess. 2021, 8, 75. [CrossRef]

2. Laougé, Z.B.; Merdun, H. Pyrolysis and combustion kinetics of Sida cordifolia L. using thermogravimetric analysis. Bioresour. Technol. 2020, 299, 122602. [CrossRef] [PubMed]

3. Statistical Review of World Energy 2021. Available online: https://www.bp.com/en/global/corporate/energy-economics/ statistical-review-of-world-energy.html (accessed on 9 July 2021).

4. Liu, J.; Jiang, X.; Cai, H.; Gao, F. Study of Combustion Characteristics and Kinetics of Agriculture Briquette Using Thermogravimetric Analysis. ACS Omega 2021, 6, 15827-15833. [CrossRef]

5. Anekwe, I.M.S.; Khotseng, L.; Isa, Y.M. The Place of Biofuel in Sustainable Living; Prospects and Challenges; Reference Module in Earth Systems and Environmental Sciences; Elsevier: Amsterdam, The Netherlands, 2021. [CrossRef]

6. Gent, S.; Twedt, M.; Gerometta, C.; Almberg, E. (Eds.) Chapter Two-Introduction to Feedstocks. In Theoretical and Applied Aspects of Biomass Torrefaction; Butterworth-Heinemann: Burlington, MA, USA, 2017; pp. 17-39.

7. Whittaker, C.; Shield, I. Factors affecting wood, energy grass and straw pellet durability-A review. Renew. Sustain. Energy Rev. 2017, 71, 1-11. [CrossRef]

8. Pradhan, P.; Mahajani, S.M.; Arora, A. Production and utilization of fuel pellets from biomass: A review. Fuel Process. Technol. 2018, 181, 215-232. [CrossRef]

9. Stolarski, M.J.; Szczukowski, S.; Tworkowski, J.; Krzyżaniak, M.; Gulczyński, P.; Mleczek, M. Comparison of quality and production cost of briquettes made from agricultural and forest origin biomass. Renew. Energy 2013, 57, 20-26. [CrossRef] 
10. Liu, J.; Cheng, W.; Jiang, X.; Muhammad, U.K.; Zhang, Q.; Cai, H. Effect of extractives on the physicochemical properties of biomass pellets: Comparison of pellets from extracted and non-extracted sycamore leaves. BioResources 2021, 15, 544-556. [CrossRef]

11. Wang, Z.; Lei, T.; Chang, X.; Shi, X.; Xiao, J.; Li, Z.; He, X.; Zhu, J.; Yang, S. Optimization of a biomass briquette fuel system based on grey relational analysis and analytic hierarchy process: A study using cornstalks in China. Appl. Energy. 2015, 157, 523-532. [CrossRef]

12. Iftikhar, M.; Asghar, A.; Ramzan, N.; Sajjadi, B.; Chen, W. Biomass densification: Effect of cow dung on the physicochemical properties of wheat straw and rice husk based biomass pellets. Biomass Bioenergy 2019, 122, 1-16. [CrossRef]

13. Rajput, S.P.; Jadhav, S.V.; Thorat, B.N. Methods to improve properties of fuel pellets obtained from different biomass sources: Effect of biomass blends and binders. Fuel Process. Technol. 2020, 199, 106255. [CrossRef]

14. Afra, E.; Abyaz, A.; Saraeyan, A. The production of bagasse biofuel briquettes and the evaluation of natural binders (LNFC, NFC, and lignin) effects on their technical parameters. J. Clean. Prod. 2021, 278, 123543. [CrossRef]

15. Liang, M.; Lu, W.; Lei, P.; Wang, L.; Wang, B.; Li, B.; Shen, Y.; Zhang, K. Physical and Combustion Properties of Binder-Assisted Hydrochar Pellets from Hydrothermal Carbonization of Tobacco Stem. Waste Biomass Valorization 2020, 11, 6369-6382. [CrossRef]

16. Lavergne, S.; Larsson, S.H.; Perez, D.D.S.; Marchand, M.; Campargue, M.; Dupont, C. Effect of process parameters and biomass composition on flat-die pellet production from underexploited forest and agricultural biomass. Fuel 2021, 302, 121076. [CrossRef]

17. Yu, Y.; Lau, A.; Sokhansanj, S. Improvement of the pellet quality and fuel characteristics of agricultural residues through mild hydrothermal treatment. Ind. Crops Prod. 2021, 169, 113654. [CrossRef]

18. Jiang, L.; Liang, J.; Yuan, X.; Li, H.; Li, C.; Xiao, Z.; Huang, H.; Wang, H.; Zeng, G. Co-pelletization of sewage sludge and biomass: The density and hardness of pellet. Bioresour. Technol. 2014, 166, 435-443. [CrossRef]

19. Degen, A.A.; Meccawi, S.E.; Kam, M. Milk and Dung Production by Yaks (Poephagus grunniens): Important Products for the Livelihood of the Herders and for Carbon Recycling on the Qinghai-Tibetan Plateau. In Carbon Management for Promoting Local Livelihood in the Hindu Kush Himalayan (HKH) Region; Springer: Cham, Switzerland, 2020; pp. 145-162. [CrossRef]

20. Bai, Y.; Rafiq, M.K.; Li, S.; Degen, A.A.; Masek, O.; Sun, H.; Han, H.; Wang, T.; Joseph, T.; Bachmann, R.T.; et al. Biochar from pyrolyzed Tibetan Yak dung as a novel additive in ensiling sweet sorghum: An alternate to the hazardous use of Yak dung as a fuel in the home. J. Hazard. Mater. 2021, 403, 123647. [CrossRef]

21. Proximate Analysis of Solid Biofuels (GB/T 28731-2012). Available online: http://www.gb688.cn/bzgk/gb/newGbInfo?hcno= E2D830152F09E47F4F6F7FF84555C30B (accessed on 5 November 2012).

22. Antony, J. (Ed.) Chapter 4-A Systematic Methodology for Design of Experiments. In Design of Experiments for Engineers and Scientists, 2nd ed.; Elsevier: Oxford, UK, 2014; pp. 33-50. [CrossRef]

23. Radi, B.; Saadoune, N.; El Hami, A. Chapter 7-Probabilistic Study and Optimization of a Solder Interconnect. In Embedded Mechatronic Systems 2, 2nd ed.; El Hami, A., Pougnet, P., Eds.; ISTE: London, UK, 2020; pp. 189-220. [CrossRef]

24. Siyal, A.A.; Liu, Y.; Mao, X.; Siyal, Z.A.; Ran, C.; Ao, W.; Fu, J.; Zhou, C.; Wang, L.; Li, X.; et al. Co-pelletization of sewage sludge, furfural residue and corn stalk: Characteristics and quality analysis of pellets. Biomass Bioenergy 2021, 150, 106121. [CrossRef]

25. Xie, R.Y.; Zhang, H.; Zhang, P.; Han, L. Effects and mechanism of pyrolysis temperature on physicochemical properties of corn stalk pellet biochar based on combined characterization approach of microcomputed tomography and chemical analysis. Bioresour. Technol. 2021, 329, 124907. [CrossRef] [PubMed]

26. Mostafa, M.E.; Hu, S.; Wang, Y.; Su, S.; Hu, X.; Elsayed, S.A.; Xiang, J. The significance of pelletization operating conditions: An analysis of physical and mechanical characteristics as well as energy consumption of biomass pellets. Renew. Sustain. Energy Rev. 2019, 105, 332-348. [CrossRef]

27. Setter, C.; Costa, K.L.S.; Oliveira, T.J.P.; Mendes, R.F. The effects of kraft lignin on the physicomechanical quality of briquettes produced with sugarcane bagasse and on the characteristics of the bio-oil obtained via slow pyrolysis. Fuel Process. Technol. 2020, 210, 106561. [CrossRef]

28. Cheng, J.; Zhou, F.; Si, T.; Zhou, J.; Cen, K. Mechanical strength and combustion properties of biomass pellets prepared with coal tar residue as a binder. Fuel Process. Technol. 2018, 179, 229-237. [CrossRef]

29. Sarker, T.R.; Nanda, S.; Meda, V.; Dalai, A.K. Pelletization of torrefied canola residue: Effects of microwave power, residence time and bio-additives on fuel pellet quality. Fuel 2022, 312, 122728. [CrossRef]

30. Wang, T.; Tang, L.; Feng, X.; Xu, J.; Ding, L.; Chen, X. Influence of organic binders on the pyrolysis performance of rice straw pellets. J. Anal. Appl. Pyrolysis 2022, 161, 105366. [CrossRef]

31. McKendry, P. Energy production from biomass (part 1): Overview of biomass. Bioresour. Technol. 2002, 83, 37-46. [CrossRef]

32. Moliner, C.; Lagazzo, A.; Bosio, B.; Botter, R.; Arato, E. Production, Characterization, and Evaluation of Pellets from Rice Harvest Residues. Energies 2020, 13, 479. [CrossRef]

33. Larsson, S.H.; Thyrel, M.; Geladi, P.; Lestander, T.A. High quality biofuel pellet production from pre-compacted low density raw materials. Bioresour. Technol. 2008, 99, 7176-7182. [CrossRef] [PubMed]

34. Kaliyan, N.; Vance, M.R. Factors affecting strength and durability of densified biomass products. Biomass Bioenergy 2009, 33, 337-359. [CrossRef]

35. Lisowski, A.; Pajor, M.; Świętochowski, A.; Dąbrowska, M.; Klonowski, J.; Mieszkalski, L.; Ekielski, A.; Stasiak, M.; Piatek, M. Effects of moisture content, temperature, and die thickness on the compaction process, and the density and strength of walnut shell pellets. Renew. Energy 2019, 141, 770-781. [CrossRef] 
36. Espuelas, S.; Marcelino, S.; Echeverría, A.M.; Castillo, J.M.; Seco, A. Low energy spent coffee grounds briquetting with organic binders for biomass fuel manufacturing. Fuel 2020, 278, 118310. [CrossRef]

37. Soleimani, M.; Tabil, X.L.; Grewal, R.; Tabil, L.G. Carbohydrates as binders in biomass densification for biochemical and thermochemical processes. Fuel 2017, 193, 134-141. [CrossRef]

38. Hu, Q.; Shao, J.; Yang, H.; Yao, D.; Wang, X.; Chen, H. Effects of binders on the properties of bio-char pellets. Appl. Energy 2015, 157, 508-516. [CrossRef]

39. Said, N.; Abdel, M.M.; Maraver, A.G.; Zamorano, M. Influence of densification parameters on quality properties of rice straw pellets. Fuel Process. Technol. 2015, 138, 56-64. [CrossRef]

40. Azargohar, R.; Nanda, S.; Kang, K.; Bond, T.; Karunakaran, C.; Dalai, A.K.; Kozinski, J.A. Effects of bio-additives on the physicochemical properties and mechanical behavior of canola hull fuel pellets. Renew. Energy 2019, 132, 296-307. [CrossRef]

41. Emadi, B.; Iroba, K.L.; Tabil, L.G. Effect of polymer plastic binder on mechanical, storage and combustion characteristics of torrefied and pelletized herbaceous biomass. Appl. Energy 2017, 198, 312-319. [CrossRef] 